\title{
Patients' handling of a standardized medication plan: a pilot study and method development
}

\author{
This article was published in the following Dove Press journal: \\ Patient Preference and Adherence \\ 22 April 2016 \\ Number of times this article has been viewed
}

\author{
Lea Botermann ${ }^{1,2}$ \\ Katrin Krueger' \\ Christiane Eickhoff' \\ Charlotte Kloft ${ }^{2}$ \\ Martin Schulz ${ }^{1-3}$ \\ 'Department of Medicine, \\ ABDA - Federal Union of German \\ Associations of Pharmacists, Berlin, \\ 2Department of Clinical Pharmacy \\ and Biochemistry, Institute of \\ Pharmacy, Freie Universitaet Berlin, \\ Berlin, ${ }^{3}$ Department of Pharmacology, \\ Goethe-University Frankfurt, \\ Frankfurt am Main, Germany
}

Purpose: The Action Plan for Medication Safety by the German Federal Ministry of Health introduced a standardized medication plan (MP), a printable document for the patient. The practical handling needs to be tested before the nationwide implementation in Germany. Therefore, the aims of our study were 1) to develop an instrument to evaluate the usage of the standardized MP, 2) to assess if patients can locate, and 3) understand important information. Moreover, we explored patients' opinion and suggestions regarding the standardized MP template.

Patients and methods: We conducted a cross-sectional study to evaluate the practical handling of the standardized MP. We interviewed 40 adult patients in seven community pharmacies in Germany, who took at least five medicines regularly and gave their written informed consent. The interview consisted of questions regarding finding and understanding information provided on a mock-up MP, patients' opinion and the execution of the information on the MP by filling pill boxes. We eventually developed a new evaluation method to quantify the practical handling of the MP by rating the pill boxes filled by the patients.

Results: Overall, the participants rated the MP positively. Thirty-nine (98\%) participants found important information on a mock-up standardized MP. Patients were questioned to identify if they understood information on medical intake as it relates to meals. In particular, they were questioned about medicine intake " 1 hour before a meal", which $98 \%(n=39)$ interpreted correctly, and "during a meal", which 100\% $(\mathrm{n}=40)$ interpreted correctly. The less precise advice of "before a meal" was interpreted correctly by $73 \%(n=29)$, and only $15 \%(n=6)$ correctly interpreted the term "after the meal". The evaluation of the filled pill boxes resulted in the "Evaluation Tool to test the handling of the Medication Plan" (ET-MP) - a weighted scoring system.

Conclusion: The standardized MP is clearly arranged, and patients are able to find important information. The findings of this study resulted in minor but important revisions of the standardized MP template. The developed evaluation tool ET-MP may serve as an objective instrument to assess patients' ability to transfer written information on the MP into practical handling of medicines.

Keywords: medication plan, medication schedule, ET-MP, Action Plan for Medication Safety, Germany, patient safety, pharmacotherapy

\section{Introduction}

The communication of medicines information is critical not only for the safe use of medicines but also, eventually, for patients' medication adherence and pharmacotherapy outcomes. Patients often misunderstand the content of physicians' or pharmacists' recommendations during counseling or they tend to forget the given information. ${ }^{1-4}$ For example, $40 \%-80 \%$ of the given information seems to be forgotten immediately. ${ }^{5}$ Patients especially fail to remember instructions on treatment. ${ }^{6}$ These facts may lead to patients' unawareness of how to take or administer their medication. For patient safety, it is crucial that patients know how to administer their medicines.
Correspondence: Martin Schulz Department of Medicine, ABDA Federal Union of German Associations of Pharmacists, Unter den Linden 19-23, 10117 Berlin, Germany

Tel $+4930400045 \mathrm{I}$ I

Fax +49304000 45I3

Email m.schulz@abda.de
Patient Preference and Adherence 2016:10 621-630

Dovepress

http://dx.doi.org/10.2147/PPA.S9643|

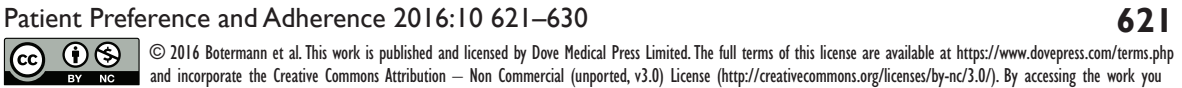
hereby accept the Terms. Non-commercial uses of the work are permitted without any further permission from Dove Medical Press Limited, provided the work is properly attributed. For permission for commercial use of this work, please see paragraphs 4.2 and 5 of our Terms (https://www.dovepress.com/terms.php). 
In general, patients better remember verbal information combined with written information than oral information alone. $^{7}$ The literature suggests that personalized prescription drug labels, containing information on, eg, dosing, may play an important role in the appropriate administration of medicines. ${ }^{8}$ But labels are effective only if people understand them, and poorly designed drug labels are even cited as a leading cause for medication errors by the American Institute of Medicine, among others. ${ }^{9}{ }^{10}$ In Germany, patients do not get personalized prescription drug labels to provide important information. Physicians are also not obligated to write dosages or medical indications on prescriptions, making it difficult for both patients and pharmacists to have a complete and comprehensive overview. Hence, in general, patients only receive selected information on their medication by the prescribing physician or the dispensing pharmacist during counseling. German studies assessing the characteristics of patients' medication lists showed that only $7 \%$ were complete and up to date. ${ }^{11}$ They were also corrected manually leaving them unreadable, ${ }^{12}$ thus showing the need for a standard.

\section{The medication plan}

A medication plan (MP) is defined as a printable document for the patient that specifies the complete medication, instructions, and indications. The MP is supposed to facilitate the correct administration of the medication after counseling in the pharmacy. ${ }^{13}$ The Action Plan for Medication Safety, ${ }^{14}$ initiated by the German Federal Ministry of Health, introduced a standardized MP template not only to aid patients but also to inform health care professionals about a patient's complete medication. ${ }^{15}$ The MP template includes prescription and nonprescription drugs and specifies the dosing regimen. This MP is going to be implemented in Germany by the so-called E-Health law, which became effective January 1, 2016 (§ 31 a Social Code Book V [Sozialgesetzbuch V $\{$ SGB V $\}$ ] - medication plan). ${ }^{16}$ Patients in the ambulatory setting insured with a statutory health insurance $(\sim 90 \%$ of the population), taking at least three prescribed medicines, are entitled to receive a paper-based MP from October 2016 onward.${ }^{16}$ For the time being, the MP is issued by the prescribing physician and shall be updated by the pharmacist during dispensing, if needed and upon patients' request, especially with regard to nonprescription pharmacy-only medicines.

Several publications identified a medication list as a relevant patient safety indicator. ${ }^{17-19}$ The MP can be considered as a combination of a medication list and the information on a personalized prescription drug label.
Like drug labels, an MP can only contribute to medication safety if patients can read and understand it. It is currently unknown if patients understand the standardized MP and can handle it. Therefore, the practical handling of the MP needs to be tested before implementation. To the best of our knowledge, no appropriate method exists to test patients' understanding and handling of an MP.

Therefore, the aims of our study were 1) to develop a new evaluation method to quantify the practical handling of the MP and 2) to evaluate if patients can find important information on the standardized MP and 3) can understand the common administering information regarding drug intake related to meals. Moreover, we aimed to explore patients' opinion and suggestions regarding the standardized MP template.

\section{Methods}

We conducted a cross-sectional study to evaluate the practical handling of the standardized MP, ${ }^{15}$ using semistructured interviews including a practical approach. In our survey, we also collected demographic data of the participants, eg, age and level of education. The comprehensibility of the interview questions was piloted with four patients. This resulted in no change of the interview guide (Supplementary materials in German and English).

Patients were eligible if they were 18 years or older, could understand and speak the German language, and gave their written informed consent. Furthermore, patients had to take at least five medicines regularly (prescription and nonprescription), as this is the most common definition for polymedication, ${ }^{20-22}$ and these patients are the main target group for the MP. The draft of the law on E-Health referred to at least five prescribed medicines as the threshold to receive a written MP. This, however, changed to three drugs during the parliamentary process. Exclusion criteria were any completed formal medical or pharmaceutical education and limited eyesight or hearing. Participants were recruited by community pharmacists. Seven pharmacies in different regions of Germany - rural and urban areas - participated in the study. They addressed appropriate patients and made an appointment for the interview. The interview was then conducted by one of the authors (LB) in a separate room within the pharmacy. We aimed to include 40 patients in total. A guideline for the readability testing of package leaflets by the European Commission suggests to include 20 patients in a user testing. ${ }^{23}$ Since this is the first study that addresses the standardized MP, we decided to double the number of patients. The study was approved by the responsible review board (data privacy commissioner in Berlin and Saxony, Germany [531.1636.11 and 2-P6805.1/4]). 


\section{The face-to-face interview}

The interviewer questioned the patients following a detailed survey guide (Supplementary materials) in a face-to-face interview, which took $\sim 1$ hour per patient. Topics were as follows: patients' understanding, their opinion, and suggestions regarding the standardized MP. We used a mock-up MP (Figure S1) for the study, which was compiled based on previous experience. The mock-up MP exemplarily listed six medicines, including prescription and nonprescription drugs with the names of brand products (eg, omeprazole as Antra MUPS ${ }^{\circledR}$ [Astra Zeneca $\mathrm{GmbH}$, Wedel, Germany]) as well as generic names (eg, metoprolol succinate as Metoprololsuccinat-1A Pharma $^{\circledR}$ [1A Pharma, Oberhaching, Germany]). The medicines had different medical indications, eg, chronic heart failure and pain. The dosing regimens covered all times of the day (morning, noon, afternoon, at bedtime) and a once-weekly administration (methotrexate). Most active ingredients were common in the general patient population, eg, metoprolol or magnesium. Administering information on the mock-up MP was selected randomly from a larger list and was easy to understand, eg, "take with a glass of water". The patients were also questioned about their attitude toward the MP. They were given four statements: "The MP is clearly arranged"; "The MP would help me to take my medication appropriately"; "I would use an MP if my doctor or pharmacist would provide one for me"; and "I would take my MP to every doctors or pharmacy appointment/visit". Then they had to state how much they agreed with the statement on a five-point Likert scale: ranging from yes (total agreement) to no (total disagreement). The interviewer documented all comments the patient made regarding the MP. The results of the patient attitude survey questions are described as numbers and percentages. Comments are stated as quotes.

Patients had 2 minutes to familiarize themselves with the MP. The first step addressed the clear arrangement of the MP. Therefore, participants had to identify important information on the document: 1) the name of the MP's author (Dr Helga Herz), 2) a medication line on the MP that corresponded to a medication package (omeprazole) shown to the patient, 3) the displayed administering information to that medicine, and 4) the medical indication column. Participants were allowed to say the answer or point out where it was found, eg, the column. The answer was incorrect if the participant pointed out the wrong column/line or could not find the information at all (Supplementary materials). The answers were analyzed descriptively as numbers and percentages.

\section{Patients' understanding of the administering information}

We also evaluated the patients' understanding of the administering information, which is included in one column of the standardized MP template. The issue of medication intake around meals is an important part of patient counseling and if relevant also mentioned in package inserts and Summaries of Product Characteristics, also as a result of the approval process. Despite the clinical significance, if instructions are given, they should be understandable to patients and/or caregivers. ${ }^{24-26}$ Hence, we investigated the understandability of these instructions and suggested improvements. There is neither a universally valid description depicted in scientific literature nor standardized definitions for what exactly they mean. Especially for the information regarding drug intake related to meals, there is no set time frame for what, eg, "before meals" or "after meals" exactly means. Thus, we predefined the appropriate time frame for this study according to clinical practice as well as our pharmacological and pharmacokinetic expertise (Figure 1).

We presented four different administering information regarding food intake (during the meal; during or after the meal; 1 hour before the meal; after the meal) to the patients. We then evaluated if the answers corresponded to the predefined definitions.

The participants were given four timelines (Figure 1). Each timeline represented 1 day from 6 until $11 \mathrm{am}$.

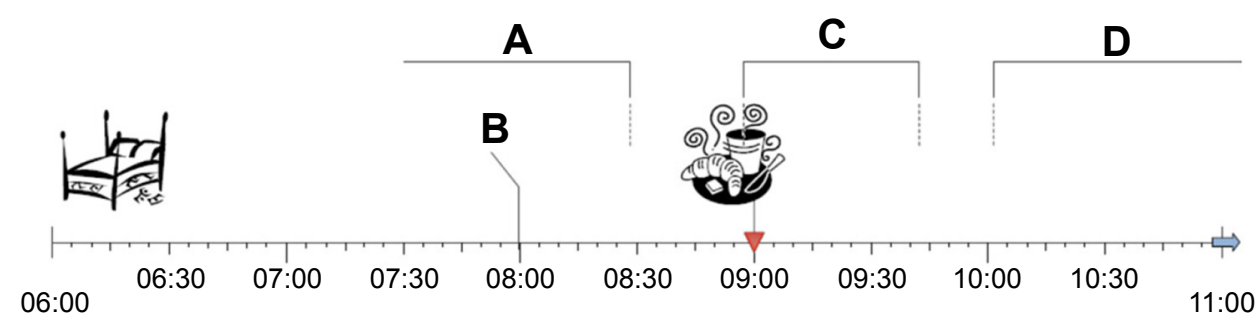

Figure I Timeline including the definitions of the administering information.

Notes: A, before the meal; B, I hour before the meal; C, during or after the meal; and $\mathbf{D}$, after the meal. 
There was a pictogram marker for the mealtime at $9 \mathrm{am}$. The participants were then asked,

Imagine you take four tablets once daily in the morning. Your pharmacist gives you the four different administering information [one for each]. When would you take each tablet? Please indicate on the timeline.

They then marked the time on the four timelines. The drawn marks were compared to the predefined time frames and counted as correct if set within them. The results are given as numbers and percentages.

\section{The practical approach of the interview}

The second part of the interview had a practical approach. Participants received the medication packages corresponding to the medicines listed on the MP (remark: in Germany, oral solid dosage forms are almost exclusively packed as blisters in a carton compared to prescription bottles). The medication packages were filled with different colored and shaped placebos including a paper pictogram representing 30 drops (Figure 2). In addition, the mock-up MP (Figure S1) and two pill boxes were handed out for 2 days (Monday and Tuesday), representative of the whole week. The interviewer then asked,

Imagine your doctor has prescribed these six medicines and he issued this medication plan in order to assist you. It lists all drugs with the corresponding dose, dosing instructions, and the medical indication. The latter written in a language understandable for patients. I would like you to show, when [at what time of the day and weekday] you would take the medication. For that, please fill the pill boxes exemplary for two days (Monday and Tuesday) according to the given dosing regimen.

Participants needed to allocate the medication cartons to the corresponding lines on the MP. They had to find and understand the dosing instruction for each medication. Finally, they needed to transfer this information into practice by filling the placebos into the compartments of the pill box (morning, noon, afternoon, at bedtime).

\section{Development of the evaluation tool}

We predefined the standard for the correct filling of the pill boxes and documented it in a picture (Figure 2). During the face-to-face interview, we also documented the results of each practical part by taking pictures. This documentation was the basis for the development of the evaluation instrument (Table S1). We evaluated the deviations from the standard and assessed the clinical relevance based on our pharmaceutical and clinical experiences and expertise.

\section{Results}

A total of 40 patients, aged 28-83 years (median 67 years), $55 \%$ female and representing the entire range of educational background, participated in the study. All completed the full interview. Patients' characteristics are displayed in Table 1.

\section{Structure of the MP template - orientation on the MP}

The author of the MP (1) was correctly depicted by $95 \%$ $(n=38)$ of the participants. One cited the wrong name and one did not find this information on the MP. All of the

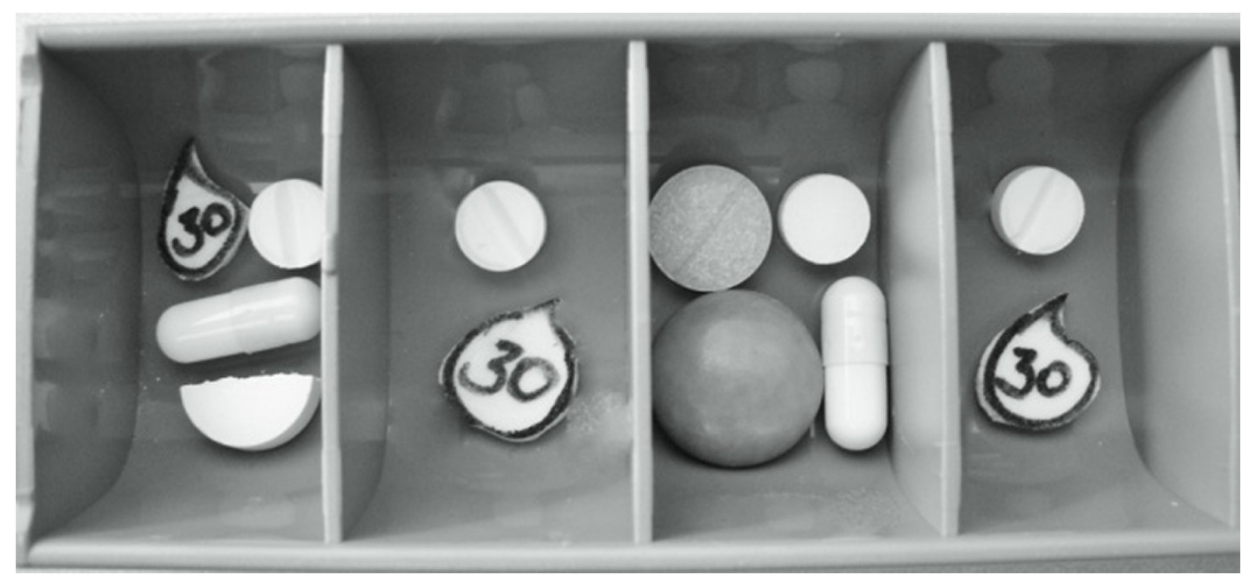

Figure 2 Correctly filled pill box (standard of the practical part).

Notes: Openings: morning, noon, afternoon, at bedtime. 
Table I Descriptive characteristics of the study group $(n=40)$

\begin{tabular}{ll}
\hline Characteristics & Median (range) or $\mathbf{n}(\%)$ \\
\hline Age (years) & $67(28-83)$ \\
Female & $22(55)$ \\
Highest completed educational degree & \\
$\quad$ None & $1(2.5)$ \\
$8 / 9$ years & $10(25)$ \\
10 years & $13(32.5)$ \\
I2/I3 years & $3(7.5)$ \\
$\quad$ University & $13(32.5)$ \\
Number of drugs & $7(5-17)$ \\
Possession of a medication list & $23(57.5)$ \\
\hline
\end{tabular}

Note: according to the patient, partly self-made and/or outdated.

participants $(n=40)$ allocated the one medication package (omeprazole) (2) correctly to the appropriate line on the MP. The corresponding administering information (3) was found by $90 \%(n=36)$. One patient assigned wrong information to the omeprazole tablets. The other three could not find the column with the administering information at all. Ninetyeight percent $(n=39)$ of the participants completed the last task (4) successfully - to show where the information regarding the medical indication is specified.

\section{Patient attitudes survey}

Overall, the participating patients rated the MP positively (Figure $3 \mathrm{~A}$ and B). Thirty-five percent $(n=14)$ were not completely satisfied with the MP design. For instance, eight patients preferred if the column with the active ingredient would be omitted and seven would swap the columns with the active ingredient and the brand name (first and second column). One patient stated 'for me as a patient it's unimportant what the active ingredient is. I can't remember it [active ingredient] anyway; I can barely even pronounce it".
Another patient is concerned "I'm totally irritated with the brand name being second [on the MP]". Thirty-five percent $(n=14)$ indicating that they would "not or rather not" take their MP to every doctor's appointment or pharmacy visit specified that they would not take it to their pharmacy because all their medication data are "saved there anyway".

\section{Patients' understanding of the administering information}

For the administering information "during or after the meal", all participants $(\mathrm{n}=40)$ marked the timeline correctly (during-30 minutes after; Figure 1). Ninety-eight percent $(n=39)$ of the patients understood the instruction " 1 hour before the meal" right. "Before the meal", defined as at least 30 minutes before, was marked correctly by only $73 \%(n=29)$ of the participants. Only $15 \%(n=6)$ marked the timeline according to the set definitions for "after the meal" as at least 60 minutes later.

\section{The evaluation tool (ET-MP)}

The comparison of the documented (photographed) pill boxes with the standard (Figure 2) showed that there were several deviations. We decided that the simple assessment of completely correct versus not completely correct filled pill boxes did not fully describe the real handling of the MP. Therefore, we identified three criteria as relevant: quantity of the medicine, day, and time of the day. These criteria needed to be applied to each day and medicine. For every day and drug, an evaluation matrix was created (Table S1). The results of the picture documentation were transferred into the matrix and rated according to the right/wrong principle (1/0). We judged that this simple assessment of the three criteria was also

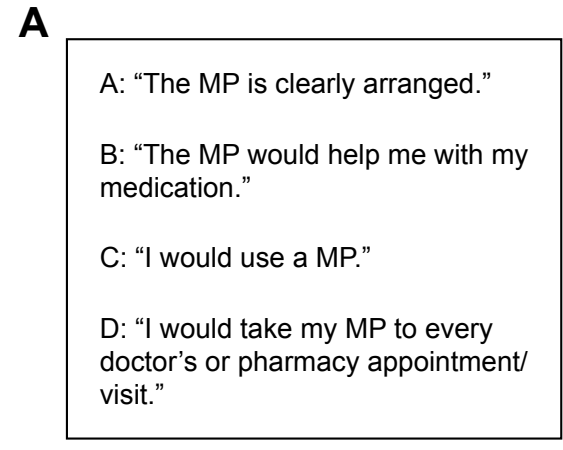

Figure 3 Attitude survey.

Notes: (A) Statements and (B) results.

Abbreviation: MP, medication plan.
B

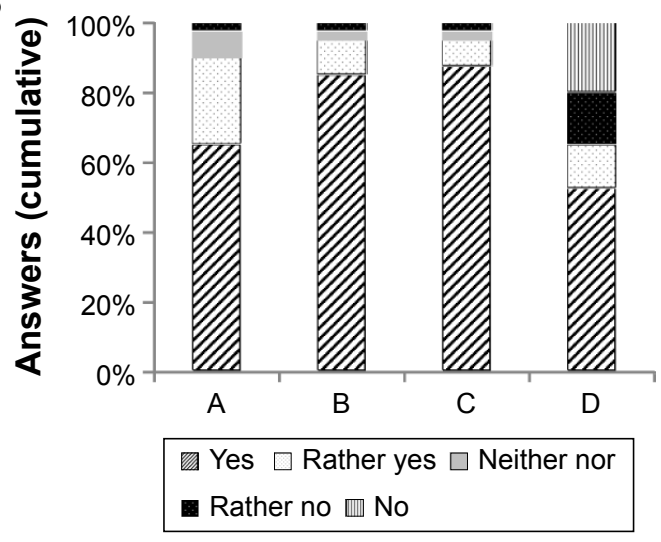


Table 2 The "Evaluation Tool to test the handling of the Medication Plan" (ET-MP)

\begin{tabular}{lll}
\hline Criteria & Correct & Incorrect \\
\hline Dosing interval including drug quantity & 3 & 0 \\
Day & 2 & 0 \\
Time of the day & 1 & 0 \\
\hline
\end{tabular}

Notes: Assessment criteria adjudged to be important. Applied to every drug on every day as a weighted point-based system.

inadequate to represent the clinical relevance sufficiently. Hence, a refinement led to a weighted scoring system. This eventually resulted in the final version of the "Evaluation Tool to test the handling of the Medication Plan" (ET-MP) (Table 2). Correctness of the three aspects was assessed as right (quantity of the medicine $=3$ points, day $=2$ points, and time of the day $=1$ point) or wrong ( 0 points). The aspects were weighted depending on the potential extend of harm an error may cause.

To quantify the patients' handling of the standardized MP, the ET-MP was applied to each day (Monday and Tuesday) and each medicine. For example, one medication is supposed to be taken every day morning and noon. The patient puts a placebo into the morning and instead of the noon opening of the pill box. The scoring would be as follows: 3 points for the correct interval and quantity (two times one tablet), 2 points for the correct day, and 0 points because it was the wrong time of the day. This would result in 5 out of 6 possible points for this selected drug and day. The total ET-MP score was calculated as the percentage of the sum of all medications for the 2 days. For the mock-up MP, this meant a maximum of 36 possible points per day and 72 possible points overall. The ET-MP score would in this case be the percentage of 72 .

\section{Discussion}

A complete and comprehensive plan of the current medication is considered to be of central importance for patient safety. We developed the ET-MP to evaluate the handling and practical usage of the standardized MP developed within the Action Plan for Medication Safety in Germany. To the best of our knowledge, this is the first evaluation tool to determine the usability of an MP. In addition, the results of the 40 interviews suggest that the current standardized MP template seems to be clearly arranged, and that patients' understanding of administering information regarding food intake depends on the type of information given.

With the standardized MP, patients have one document that lists the complete medication including the dosing regimen, administering information, and medical indication.
It has been shown that misunderstandings and medication errors can be avoided and medication reconciliation and adherence might be improved. ${ }^{27}$ Different international patient safety initiatives emphasize a medication list or schedule as a central patient safety indicator. They state that patients with multiple pharmacotherapy (polymedication) are urged to always have a complete list of all their medicines with them. ${ }^{17,28}$ Send et al showed that an MP including dosing and administering instructions can also support verbal instructions at hospital discharge, leaving patients significantly better informed; ${ }^{29}$ thus, making it also easier for the patients to take an active part in the decision-making process. A recent study, assessing characteristics of MP used by elderly ambulatory patients in Germany, showed that only a fraction already possessed an MP. ${ }^{12}$ Half of these MPs were amended manually with the risk to confuse both the user (patient or carer) and health care professionals. ${ }^{12}$ This supports the need for a nationally standardized MP.

For the developed MP standard ${ }^{15}$ to be usable, it is essential that it is clearly arranged and that patients can identify all the relevant information. ${ }^{30}$ In our study, almost all participants were able to find the important information on the MP. The participants had only minor suggestions for improvement.

As an important by-product of the interview, we found that the abbreviations used for representing the time of the day in the dosing column were unclear. The abbreviations "mo" and "mi" were misunderstood as Monday (German: Montag) and Wednesday (Mittwoch); instead of morning (German: morgens) and noon (mittags). The abbreviation "zN" for at bedtime (German acronym for zur Nacht) seemed not to be self-explanatory either. This resulted in confusion and uncertainty. Fifty percent $(n=20)$ of the participants made comments indicating misunderstanding of the abbreviations; $17.5 \%(\mathrm{n}=7)$ did not understand the naming of the time of the day even after an explanation. This fact could be an important threat to patient safety. We therefore strongly recommend revising the standardized MP template and writing out the time of the day to avoid confusion.

Regarding administering information, there is neither a universally valid description depicted in scientific literature nor standardized definitions for what exactly they mean. Precise instructions, like "1 hour before the meal", were understood correctly by almost all the participants. Vague wording of the administering information leads to widely spread answers of the participants. For example, for "before the meal" the answers reached from 5 to 90 minutes before the meal (median $=30)$. Gazmararian et al showed that over 
half of their participants could not answer "how to take medication on an empty stomach". ${ }^{31}$ To promote medication safety, it is desirable and necessary to not only use precise instructions but also have standardized phrases for the MP. ${ }^{32}$

Davis et al showed that patients can better verbalize than demonstrate read information. ${ }^{4}$ This means though many patients can reproduce given information, they have not fully understood it (lack of comprehension). Therefore, our study applied a practical part in addition to the allocation of important information on the MP. We decided to look at 2 days (Monday and Tuesday) as representative for the entire week. By including 2 days compared to just 1 day, we intended to capture more complex dosing regimens, eg, once a week on Monday. It is possible that the results would differ if the test would include more days or even the whole week. But within this study, this was deemed not feasible.

We developed the ET-MP to evaluate the handling of MP by the patients. Therefore, we assessed every medicine and every day separately including three aspects rated as relevant. We found it necessary that the scoring height of the different aspects depends on the potential harm a medication error could cause, resulting in the weighted scoring system (Table 2). The final ET-MP score is the percentage of the individual points based on the maximum points.

The strength of our study is that we developed the first instrument to evaluate the handling of an MP with the help of the ET-MP. The ET-MP is easy to apply and to calculate, and patients appreciated this type of interview. None of the 40 patients found the approach offensive. The instrument also seems applicable to study patients' handling of an MP.

A limitation is that we did not assess health literacy of the study participants. But to the best of our knowledge, there is no validated tool to assess health literacy in German patients. We therefore included the participants' level of education. A further limitation is that the tool was developed on a relatively small sample size. However, the European Commission only requires $\mathrm{N}=20$ for package insert readability testing. To assure the feasibility of the instrument as well as sufficient inter-rater reliability, it is desirable to further test the tool on a larger sample and even on patients with certain medical indications, such as applying the tool to patients suffering from, eg, chronic heart failure, diabetes, or depression. To determine the understandability of the MP, a cutoff needs to be defined on the basis of a greater sample. It should then be analyzed if certain patient characteristics are associated with the understandability of the MP. Another potential limitation of our study, due to the design, is an interviewer bias. We however considered the robust methodology of a single interviewer to be superior to the risk of an interviewer bias in this pilot investigation and method development. We, furthermore, did not hypothesize the results and should have therefore avoided desired responses as much as possible.

\section{Conclusion}

Our research shows that the standardized $\mathrm{MP}^{15}$ is clearly arranged and patients are able to find important information on it. In general, the patients are satisfied with the MP and would appreciate if they obtained one. They see the need for a complete list of all their medication with the corresponding dosing regimen and administering information.

For the standardized MP, it is important to have standards not only regarding the format but also regarding the content, eg, the wording of administering information, which needs to be precise and understandable. For the future, it is desirable to conduct a further and broader test of the MP with the developed instrument, the ET-MP.

\section{Acknowledgments}

The authors would like to thank the seven community pharmacies for their support provided in recruiting the participants for this study. This work was funded by a grant from the German Federal Ministry of Health as part of the project PRIMA (Primaersystem-Integration des Medikationsplans mit Akzeptanzuntersuchung, ref no 2514ATS001).

\section{Disclosure}

The authors report no conflicts of interest in this work. The work described in this paper forms part of the planned doctoral thesis (Dr rer nat) of Lea Botermann.

\section{References}

1. Fletcher SW, Fletcher RH, Thomas DC, Hamann C. Patients' understanding of prescribed drugs. J Community Health. 1979;4(3):183-189.

2. Williams MV, Parker RM, Baker DW, et al. Inadequate functional health literacy among patients at two public hospitals. JAMA. 1995; 274(21):1677-1682.

3. McCarthy DM, Cameron KA, King JP, et al. Patient recall of health care provider counseling for opioid-acetaminophen prescriptions. Pain Med. 2014; 15(10):1750-1756

4. Davis TC, Wolf MS, Bass PF 3rd, et al. Literacy and misunderstanding prescription drug labels. Ann Intern Med. 2006;145(12):887-894.

5. McGuire LC. Remembering what the doctor said: organization and adults' memory for medical information. Exp Aging Res. 1996;22(4):403-428.

6. Kessels RP. Patients' memory for medical information. $J$ R Soc Med. 2003;96(5):219-222.

7. Tarn DM, Heritage J, Paterniti DA, Hays RD, Kravitz RL, Wenger NS Physician communication when prescribing new medications. Arch Intern Med. 2006;166(17):1855-1862. 
8. Blinder D, Rotenberg L, Peleg M, Taicher S. Patient compliance to instructions after oral surgical procedures. Int J Oral Maxillofac Surg. 2001;30(3):216-219.

9. Aspden P, Wolcott J, Bootman JL, Cronenwett LR. Preventing Medication Errors: Quality Chasm Series. Washington, DC: National Academies Press; 2007.

10. Shrank W, Avorn J, Rolon C, Shekelle P. Effect of content and format of prescription drug labels on readability, understanding, and medication use: a systematic review. Ann Pharmacother. 2007;41(5): 783-801.

11. Waltering I, Schwalbe O, Hempel G. Discrepancies on medication plans detected in German community pharmacies. J Eval Clin Pract. 2015;21(5):886-892.

12. Freigofas J, Seidling HM, Quinzler R, et al. Characteristics of medication schedules used by elderly ambulatory patients. Eur J Clin Pharmacol. 2015;71(9):1109-1120.

13. Botermann L, Schulz M. Grundlegende Voraussetzungen für die elektroni-sche Abbildung von Arzneimitteldaten im Hinblick auf den Medikationsplan: Aktionsplan Arzneimitteltherapiesicherheit (AMTS) des Bundesministeriums für Gesundheit (BMG). [Abschlussbericht]; [Essential requirements for the electronic imaging of medication data with regard to the medication plan: action plan for medication safety (final report)] 2014. German. Available from: https://www.bundesgesundheitsministerium.de/fileadmin/dateien/Publikationen/Gesundheit/ Forschungsberichte/Abschlussbericht_Grundlegende_Voraussetzungen_fuer_die_elektronische_Abbildung.pdf. Accessed February 9, 2016.

14. Bundesministerium für Gesundheit. Aktionsplan 2013-2015 des Bundesministeriums für Gesundheit zur Verbesserung der Arzneimitteltherapiesicherheit in Deutschland. [Aktionsplan AMTS 2013-2015]. [German Federal Ministry of Health. Action plan for medication safety 2013-2015 by the German Federal Ministry of Health] Bonn; 2013. German. Available from: http://www.akdae.de/AMTS/Aktionsplan/ index.html. Accessed February 9, 2016.

15. Koordinierungsgruppe zur Umsetzung und Fortschreibung des Aktionsplanes zur Verbesserung der Arzneimitteltherapiesicherheit in Deutschland. Spezifikation für einen patientenbezogenen Medikationsplan: Version 2.0 - für Modellvorhaben; [Coordination group Action Plan for medication safety. Specification for a patientrelated medication plan: Version 2.0 for pilot testing] 2013. German. Available from: http://www.akdae.de/AMTS/Medikationsplan/index. html. Accessed February 9, 2016.

16. Gesetz für sichere digitale Kommunikation und Anwendungen im Gesundheitswesen: E-Health-Gesetz; [Law on the safe digital communication and applications in health care - e-health law]. Available from: http://www.bgbl.de/xaver/bgbl/start.xav?startbk=Bundesanzeiger_ BGB1\&jumpTo=bgb1115s2408.pdf. Updated December 21, 2015. Accessed February 19, 2016.

17. Committee on Identifying and Preventing Medication Errors. What can you do to avoid medication errors: fact sheet. 2006. Available from: http://iom.nationalacademies.org/ /media/Files/Report $\% 20$ Files/2006/Preventing-Medication-Errors-Quality-Chasm-Series/ medicationerrorsfactsheet.pdf. Accessed February 9, 2016.

18. Wenger NS, Young RT. Quality indicators for continuity and coordination of care in vulnerable elders. J Am Geriatr Soc. 2007; 55(Suppl 2):S285-S292.
19. Kuske S, Lessing C, Lux R, Schmitz A, Schrappe M. Patientensicherheitsindikatoren zur Arzneimitteltherapiesicherheit (AMTS-PSI): Internationaler Status, Übertragbarkeit und Validierung [Patient safety indicators for medication safety (AMTS-PSI): international status, transferability and validation]. Gesundheitswesen. 2012;74(2):79-86. German.

20. Schwabe U, Paffrath D. Arzneiverordnungs-Report 2015: Aktuelle Zahlen, Kosten, Trends und Kommentare. [drug prescription report 2015: current numbers, costs, trends and comments] Springer-Verlag; Berlin Heidelberg, 2015.

21. Viktil KK, Blix HS, Moger TA, Reikvam A. Polypharmacy as commonly defined is an indicator of limited value in the assessment of drug-related problems. Br J Clin Pharmacol. 2007;63(2):187-195.

22. Gurwitz JH, Field TS, Harrold LR, et al. Incidence and preventability of adverse drug events among older persons in the ambulatory setting. JAMA. 2003;289(9):1107-1116.

23. Guideline on the readability of the labelling and package leaflet of medicinal products for human use [webpage on the Internet]; 2009. Available from: http://ec.europa.eu/health/files/eudralex/ vol-2/c/2009_01_12_readability_guideline_final_en.pdf. Accessed February 9, 2016.

24. Thai M, Reeve E, Hilmer SN, Qi K, Pearson S, Gnjidic D. Prevalence of statin-drug interactions in older people: a systematic review. Eur J Clin Pharmacol. Epub 2016 Jan 20.

25. Irving SA, Vadiveloo T, Leese GP. Drugs that interact with levothyroxine: an observational study from the Thyroid Epidemiology, Audit and Research Study (TEARS). Clin Endocrinol. 2015;82(1):136-141.

26. Misaka S, Yatabe J, Müller F, et al. Green tea ingestion greatly reduces plasma concentrations of nadolol in healthy subjects. Clin Pharmacol Ther. 2014;95(4):432-438.

27. Wolf MS, Curtis LM, Waite K, et al. Helping patients simplify and safely use complex prescription regimens. Arch Intern Med. 2011;171(4): 300-305.

28. Koordinierungsgruppe zur Umsetzung und Fortschreibung des Aktionsplanes zur Verbesserung der Arzneimitteltherapiesicher-heit in Deutschland. Tipps für eine sichere Arzneimitteltherapie. [Coordination group Action Plan for medication safety. Notes for a safe drug therapy - patient information]. Available from: https://www. bundesgesundheitsministerium.de/fileadmin/dateien/Publikationen/ Gesundheit/Sonstiges/Faltblatt_Informationsmerkblatt_fuer_ Patientinnen_und_Patienten_mit_8_Tipps_fuer_eine_sichere_ Arzneimitteltherapie.pdf. Accessed February 9, 2016.

29. Send AF, Schwab M, Gauss A, Rudofsky G, Haefeli WE, Seidling HM. Pilot study to assess the influence of an enhanced medication plan on patient knowledge at hospital discharge. Eur J Clin Pharmacol. 2014; 70(10):1243-1250.

30. Fuchs J, Hippius M, Schaefer M. Analysis of German package inserts. Int J Clin Pharmacol Ther. 2006;44(1):8-13.

31. Gazmararian JA, Baker DW, Williams MV, et al. Health literacy among Medicare enrollees in a managed care organization. JAMA. 1999;281(6):545-551.

32. Koster ES, Blom L, Winters NA, van Hulten RP, Bouvy ML. Interpretation of drug label instructions: a study among four immigrants groups in the Netherlands. Int J Clin Pharm. 2014;36(2):274-281. 


\section{Supplementary materials}

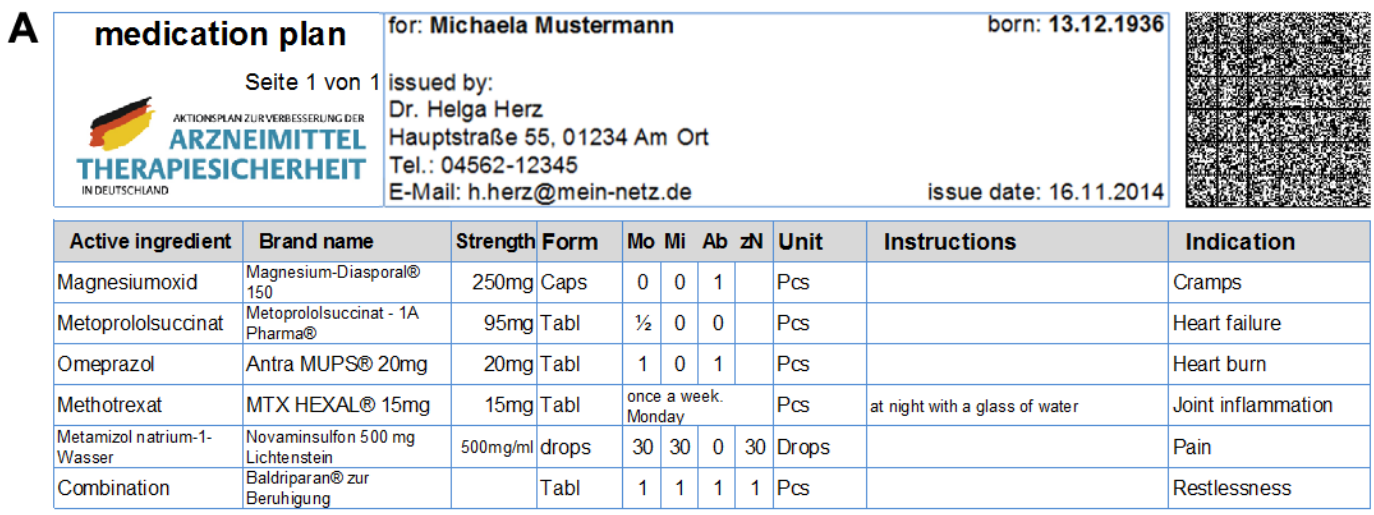

important information

please meassure your blood preassure daily!

\begin{tabular}{|c|c|c|c|c|c|c|c|c|c|c|c|}
\hline \multicolumn{2}{|c|}{$\begin{array}{r}\text { kationsplan } \\
\text { Seite } 1 \text { von }\end{array}$} & \multicolumn{6}{|c|}{$\begin{array}{l}\text { für: Michaela Mustermann } \\
\text { ausgedruckt von: } \\
\text { Dr. Helga Herz } \\
\text { Hauptstraße } 55,01234 \text { Am Ort } \\
\text { Tel.: } 04562-12345 \\
\text { E-Mail: h.herz@mein-netz.de }\end{array}$} & & \multicolumn{2}{|r|}{ ausgedruckt am: 16.11 .2014} & \multirow[t]{2}{*}{ 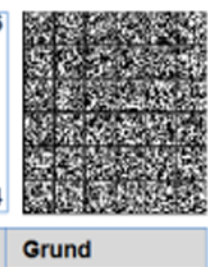 } \\
\hline Wirkstoff & \multicolumn{2}{|c|}{ Handelsname } & \multirow{2}{*}{\begin{tabular}{|r|} 
Stärke \\
$250 \mathrm{mg}$
\end{tabular}} & \multirow{2}{*}{\begin{tabular}{|l|} 
Form \\
Kaps
\end{tabular}} & \multicolumn{2}{|c|}{ Mo Mi } & \multicolumn{2}{|c|}{$A b \geq N$} & \multirow{2}{*}{ Einheit } & \multirow[t]{2}{*}{ Hinweise } & \\
\hline Magnesiumoxid & $\begin{array}{l}\text { Magnesium-Dias } \\
150\end{array}$ & & & & 0 & 0 & 1 & & & & Wadenkrämple \\
\hline Metoprololsuccinat & $\begin{array}{l}\text { Metoprodolsucona } \\
\text { Pharmase }\end{array}$ & & $95 \mathrm{mg}$ & Tabl & $1 / 2$ & 0 & 0 & & Stock & & Herzinsuffizienz \\
\hline Omeprazd & Antra MUPSB & $20 \mathrm{mg}$ & $20 \mathrm{mg}$ & Tabl & 1 & 0 & 1 & & Stûck & & Sodtrennen \\
\hline Methotrexat & MTX HEXALO & $15 \mathrm{mg}$ & $15 \mathrm{mg}$ & Tabl & & $\begin{array}{l}\text { ochen } \\
\text { tags }\end{array}$ & & & Stack & Abends m\& einem Glas Wasser & Gelenkentzundung \\
\hline $\begin{array}{l}\text { Metamizol natium-1. } \\
\text { Wasser }\end{array}$ & $\begin{array}{l}\text { Novaminsuloon } 5 \mathrm{C} \\
\text { Lichtensten }\end{array}$ & & $500 \mathrm{mg} / \mathrm{ml}$ & Tropfen & 30 & 30 & 0 & 30 & Tropfen & & Schmerzen \\
\hline Kombi-Prăp. & $\begin{array}{l}\text { Baichias ande aur } \\
\text { Beruhigung }\end{array}$ & & & Tabl & 1 & 1 & 1 & 1 & Stûck & & Unruhe \\
\hline
\end{tabular}

\section{Wichtige Angaben}

Bitte messen Sie Ihren Blutdruck tăgich!

Figure SI Mock-up medication plan (MP).

Notes: (A) English translation (not authorized). (B) Original MP in German as it was used in the study. The MPs display dummy data and do not represend a real patient's information or medication. 
Table SI "Evaluation Tool to test the handling of the Medication Plan" (ET-MP) evaluation example: two sample days with perfectly filled pill boxes (the standard)

\begin{tabular}{|c|c|c|c|c|c|c|}
\hline \multicolumn{4}{|l|}{ Monday } & \multicolumn{3}{|l|}{ Tuesday } \\
\hline Drug (product) & Interval plus quantity & Day & Time of day & Interval plus quantity & Day & Time of day \\
\hline Magnesium & $3 / 3$ & $2 / 2$ & $\mathrm{I} / \mathrm{I}$ & $3 / 3$ & $2 / 2$ & $1 / 1$ \\
\hline Metoprolol succinate & $3 / 3$ & $2 / 2$ & $\mathrm{I} / \mathrm{I}$ & $3 / 3$ & $2 / 2$ & $1 / 1$ \\
\hline Omeprazole & $3 / 3$ & $2 / 2$ & $\mathrm{I} / \mathrm{I}$ & $3 / 3$ & $2 / 2$ & $1 / 1$ \\
\hline Methotrexate & $3 / 3$ & $2 / 2$ & $\mathrm{I} / \mathrm{I}$ & $3 / 3$ & $2 / 2$ & $1 / 1$ \\
\hline Metamizole/Dipyrone & $3 / 3$ & $2 / 2$ & $\mathrm{I} / \mathrm{I}$ & $3 / 3$ & $2 / 2$ & $1 / 1$ \\
\hline Baldriparan ${ }^{\circledR}$ & $3 / 3$ & $2 / 2$ & $1 / 1$ & $3 / 3$ & $2 / 2$ & $\mathrm{I} / \mathrm{I}$ \\
\hline
\end{tabular}

Notes: Data presented as points achieved/points possible. Result: 72/72 = 100\% (ET-MP - Score). Assessment: The three aspects of the tool (interval plus quantity; day; time of day) are applied to every drug and every day, respectively. if the aspects are correct full points $(3,2$ or I) are given. If the aspects are wrong 0 points would be assigned.

\section{Publish your work in this journal}

Patient Preference and Adherence is an international, peer-reviewed, open access journal that focuses on the growing importance of patient preference and adherence throughout the therapeutic continuum. Patient satisfaction, acceptability, quality of life, compliance, persistence and their role in developing new therapeutic modalities and compounds to optimize clinical outcomes for existing disease states are major areas of interest for the journal. This journal has been accepted for indexing on PubMed Central. The manuscript management system is completely online and includes a very quick and fair peer-review system, which is all easy to use. Visit http://www dovepress.com/testimonials.php to read real quotes from published authors.

Submit your manuscript here: http://www.dovepress.com/patient-preference-and-adherence-journal 